\title{
PROTECTION SEQUENCE OF AC/DC CONVERTERS FOR ITER PF MAGNET COILS
}

\author{
BYUNG-HOON OH*, CHURL-KEW HWANG, KWANG-WON LEE, JEONG-TAE JIN, DAE-SIK CHANG, \\ JONG-SEOK OH ${ }^{1}$, JUNGWAN CHOI ${ }^{1}$, JAE HAK SUH ${ }^{1}$, JUN TAO ${ }^{2}$ and INHO SONG ${ }^{2}$ \\ Korea Atomic Energy Research Institute, Daejeon, 305-353, Korea \\ ${ }^{1}$ Nuclear Fusion Research Institute, Daejeon, 305-806, Korea \\ ${ }^{2}$ ITER Organization, St Paul Lez Durance, France \\ ${ }^{*}$ Corresponding author. E-mail : bhoh@kaeri.re.kr
}

Received September 11, 2009

Accepted for Publication March 24, 2010

The protection sequence of an AC/DC converter for an ITER PF coil system is developed in this study. Possible faults in the coil system are simulated and the results reflected in the design of a sequence to protect the coil and converter. The inductances of the current sharing reactors and thyristor numbers in parallel with the bridge arms are optimized with the designed protection sequence.

KEYWORDS : AC/DC Converter, Protection, DC Short, Misfiring, Bypass, Parallel Thyristor

\section{INTRODUCTION}

The magnet system of an ITER machine is composed of several large superconducting coils that produce and sustain the plasma current during long pulse operation. These include toroidal field (TF) coils, central solenoid (CS) coils, poloidal field (PF) coils, and correction coils (CC), as shown in Fig. 1. The coil power supply and distribution system [1] provide pulsed power to the TF, $\mathrm{PF}, \mathrm{CS}$, and correction coils. The system also provides protection for the coils in the event of quenches, in the event of over-current or over-voltage due to abnormal or fault conditions in the power supply, and in the event of earth faults.

- The currents that power the coils are controlled by AC/DC converters [2]. The energy stored in the coils while operating under a tokamak condition is very high (for example, the energy stored in toroidal field coils is $40 \mathrm{GJ}$ ), and the rated current of the converters is very high (the rated current and voltage of the Main Converter are $55 \mathrm{kA}$ and $2 \mathrm{kV}$, respectively). Therefore, a proper protection sequence of the coil power supply system for normal and abnormal conditions is very important to protect the superconducting coils and $\mathrm{AC} / \mathrm{DC}$ converters from severe damage. In this paper, a protection sequence including the determination of the circuit parameters of the AC/DC converters of a $\mathrm{PF}$ system [3] along with simulation results of while the potential faults components are in operation are discussed.
The contents of this paper include the following:

- AC/DC converters for an ITER PF coil system

- Possible faults and simulation results

- The protection sequence and simulation results

- The design parameters of the converters circuits

\section{AC/DC CONVERTERS FOR ITER PF COIL SYSTEM}

There are six PF coils (PF1 to PF6) whose main roles are shaping the cross-section and controlling the position of the plasma. The coils at the outside from the center (from PF2 to PF5) are used to stabilize the plasma vertical position. The quasi-symmetrical distribution of the currents in these coils makes it possible to use a single fast-response thyristor converter dedicated to plasma stabilization. This is connected to the coils as shown schematically in Fig. 2. This figure also shows that two pairs of the quasi-symmetrical coils (PF2-PF5 and PF3-PF4) are connected in parallel to what is known as a vertical stabilization (VS) converter. Within each pair, the two coils are connected in an antiparallel design. The booster Converter (BC), which has a relatively high voltage rating, is used only during the plasma initiation phase. The main converter (MC) is commonly used for all of the PF coils. In this paper, MC, $\mathrm{VS}$ and $\mathrm{BC}$ converter systems are investigated.

\subsection{Converter}

The electric schematic of a MC unit is shown in Fig. 3. 


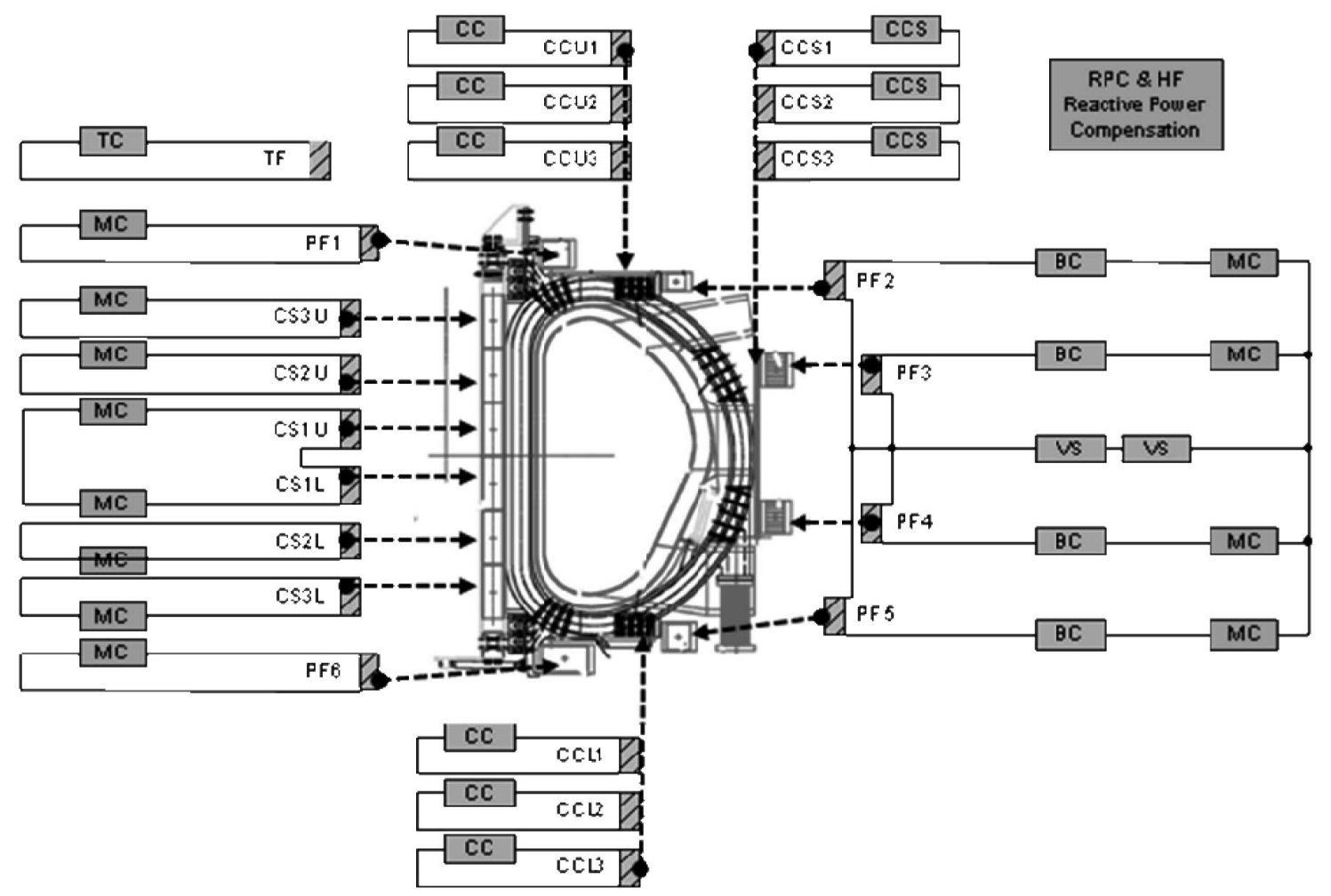

Fig. 1. Schematic Diagram of the ITER Magnet System

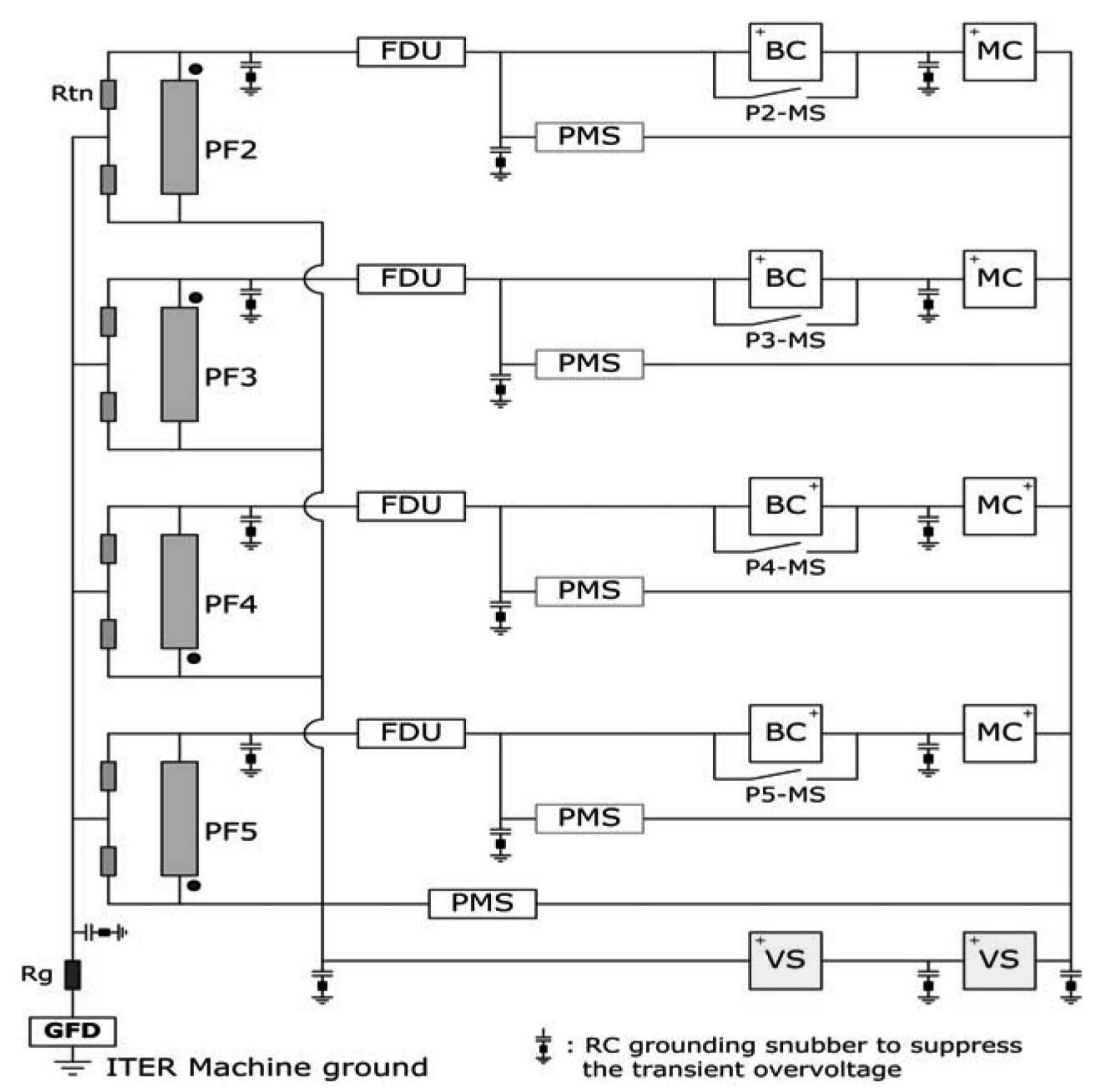

Fig. 2. Schematic Diagram of the Power Supply System for the PF2, PF3, PF4, and PF5 Coils 


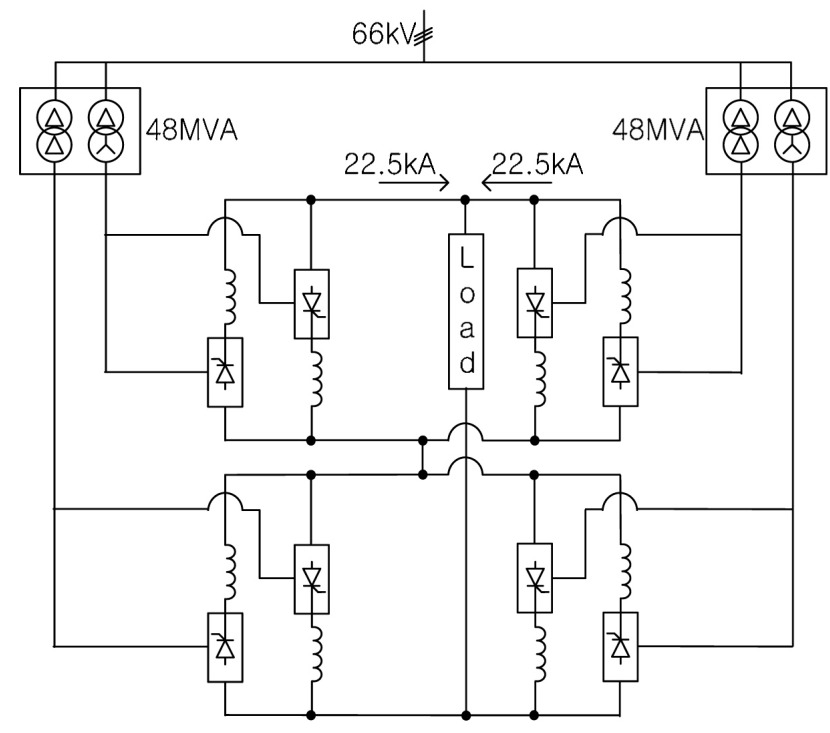

Fig. 3. Schematic Circuit Diagram of the MC Converter

This is a 12-pulse, 4-quadrant converter that uses backto-back bridges. The MC converter, rated for $55 \mathrm{kA}$ and $2 \mathrm{kV}$ (no-load), operates in 6-pulse current-circulating mode (in one bridge with "forward" thyristors and in the second with "backward" thyristors) when the absolute value of the current is below $10 \%$ of the maximum current. This avoids the danger of current extinction upon zero crossing. Each unit $(1 \mathrm{kV}, 22.5 \mathrm{kA}$ rate) is suitable for connection in series and/or in parallel with other units. Each MC unit is connected to $66 \mathrm{kV}$ bus-bars through two rectifier transformers, whose nominal power is $48 \mathrm{MVA}$.

\subsection{BC Converter}

The $\mathrm{BC}$ converter, rated for $10 \mathrm{kA}$ and $5.6 \mathrm{kV}$ (no load), consists of two 12-pulse rectifiers connected in an anti-parallel array. Each rectifier consists of two thyristor bridges connected in series and fed by two different secondary windings of the transformer (see Fig. 4). The 12-pulse operation is assured by the connection to the secondary windings of both transformers and remains even during circulating current operation. Circulating current operation is activated when the absolute value of the current is less than $10 \%$ of the maximum current. Each BC converter is connected to the $66 \mathrm{kV}$ bus-bars through two rectifier transformers, the rated power of which is 30 MVA.

\subsection{VS Converter}

Series-connected VS converter units that serve as a vertical stabilization converter are used in the coil PF2PF5 integrated PS system (see Fig. 2). As compared to the MC converters included in series with each coil, the VS converter has a significantly higher output voltage and faster response time. Each VS converter unit is rated

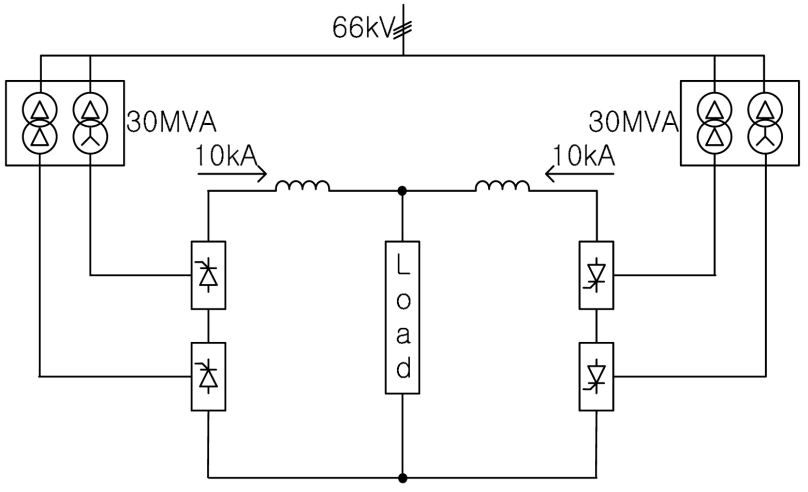

Fig. 4. Schematic Circuit Diagram of the BC Converter

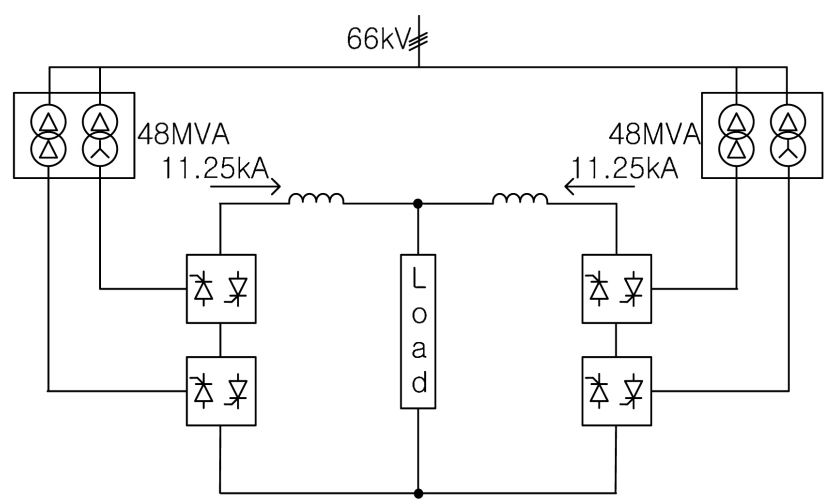

Fig. 5. Schematic Circuit Diagram of the VS Converter

for $22 \mathrm{kA}$ and $8 \mathrm{kV}$ (no load) and consists of four 6-pulse back-to-back thyristor bridges combined into two 12pulse groups, with two groups of series-connected bridges in parallel through an inter-phase reactor (see Fig. 5). When the output current is within approximately $\pm 10 \%$ of its maximum power, it continues to operate while circulating current as a 12-pulse thyristor rectifier in order to maintain its fast dynamic characteristics under all operating conditions. The polarity change procedure is identical to that of the MC converter. Each VS converter unit is connected to $66 \mathrm{kV}$ bus-bars through two rectifier transformers, the rated power of which is $48 \mathrm{MVA}$.

\subsection{Design Issues of the PF Converter}

As ITER demands very high power during the pulse, there are additional critical issues to be addressed when designing the AC/DC converters. The following issues must be considered in the design of a PF coil system:

- Fault current issues related to the junction temperatures of the thyristors during fault events

- The use of an efficient and reliable bypass method

- The use of a reactive power reduction method [4]

- Optimization of the inductance of the DC Reactor (DCR) 


\section{POSSIBLE FAULTS AND SIMULATION RESULTS}

All of the currents of the coils are supplied by parallelconnected converters through DCRs, which are used to balance the parallel currents. Additionally, to meet the voltage rating (BC and VS cases) or to decrease the reactive power generation ( $\mathrm{MC}$ case), the same modules are connected in series. Moreover, converter unit modules (MC case) or thyristor arms (VS case) utilize a back-toback connection to achieve 4-quadrant operation. Therefore, there are many different possible faults in the converters, such as DC shorting and misfiring. DC shorting is an accident in a DC line before and after a DCR that is caused by an accident or malfunction of the switches in the power supply circuit. Misfiring of a back-to-back connected thyristor can also lead to an ac short through the misfired thyristor. The serious faults that should be considered in the design are summarized in Table 1 and are schematically shown in Fig. 6.

Table 1. Fault Conditions Considered in the Design

\begin{tabular}{c|l|c}
\hline & \multicolumn{1}{|c}{ DC short } & Misfiring \\
\hline $\begin{array}{c}\text { MC } \\
\text { converter }\end{array}$ & $\begin{array}{l}\text { - unit module arm short } \\
\text { - parallel module arm short } \\
\text { - series module arm short }\end{array}$ & Considered \\
\hline \multirow{3}{*}{ VS converter } & $\begin{array}{l}\text { - unit module arm short } \\
\text { - series module arm short } \\
\text { - parallel module arm short }\end{array}$ & Considered \\
\hline BC converter & $\begin{array}{l}\text { - series module arm short } \\
\text { - parallel module arm short } \\
\text { - coil short }\end{array}$ & Not considered \\
\hline
\end{tabular}

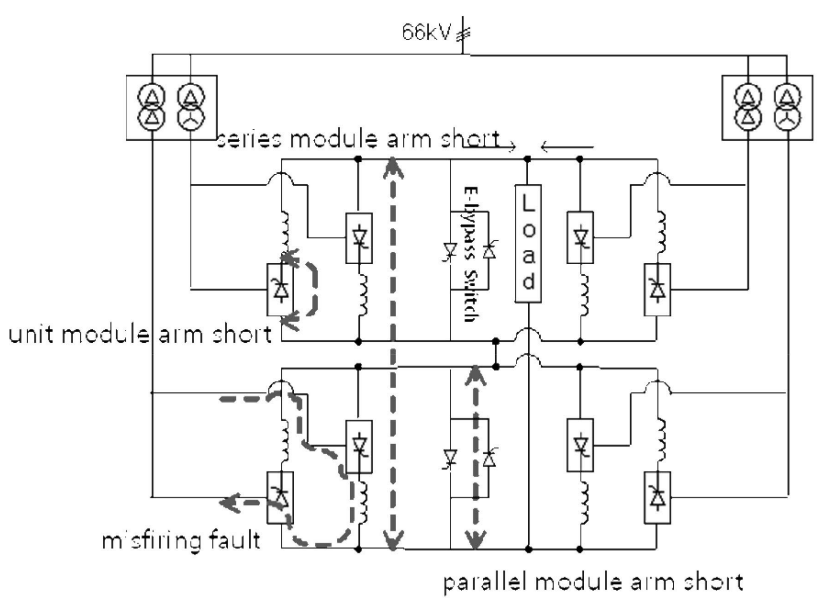

Fig. 6. Schematic for Serious Faults (Four Cases) in the MC Converter
Faults in the converters were simulated using related modules. The alpha angles of the bridges were set to zero (max. voltage) to simulate the most serious case. During a misfiring fault, two line ac-short current flows through the misfired thyristor, and the fault current does not stop, even after gate blocking, because the thyristor current retains a positive value after an ac cycle. A fast gate block within $10 \mathrm{msec}$ can terminate the latch of these fault currents. The maximum peak current is determined by the DCR size, and the thyristor that is most heated becomes the misfired back-to-back thyristor. During a DC short, the maximum short current is determined by the transformer impedance, DC output voltage and/or DCR size depending on the position of the short. The fault current can be minimized by controlling the gate and bypass switches. The fault scenarios and the results are discussed along with the protection sequences in the following sections.

\section{PROTECTION SEQUENCES}

When a fault occurs, the power supply system should protect the magnet coils and converters and safely discharge the energy stored in the system. The protection sequence must accomplish this using bypass switches such as an ebypass (electrical bypass) component and a Protection Make Switch (PMS), which are the main components of the protection circuit. The e-bypass component is close to the converters and the PMS is close to the magnet coils (see Fig. 6).

For simplicity and reliability, the use of a single protection sequence to cover all faults is preferable. The line with the white box in Fig. 7 shows the normal protection sequence of the converter against faults. The following sequence and current flows can be made during the sequence: (1) all of the gates of the converters are blocked, and the latching current of the converters and coil current then flow through the secondary winding of the transformer;

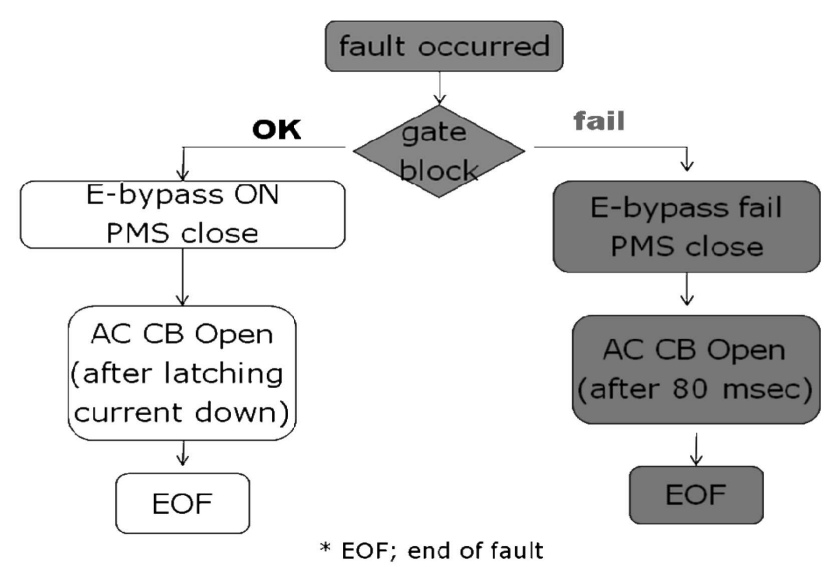

Fig. 7. Flow Diagram of the Protection Sequence 
(2) e-bypass is ON, and the coil current then starts to flow through the bypass; (3) the PMS bypass switch is closed, and the coil current is then transferred from e-bypass to PMS; (4) the AC CB (Circuit Breaker) is open after the latching current goes down to zero, which finishes the protection sequence. AC CB should not be opened when DC component remains active due to the induced voltage in the circuit. The decreasing rate of the latching current depends on the bus-bar time constant, and this is related to the junction temperature. For the MC case, the time constant is 0.3 seconds.

It is considered as a double fault when the above protection sequence does not operate properly. A double fault occurs when a fault has occurred but gate block and e-bypass procedures have failed. In this double fault condition, the following scenario can arise, as shown in Fig. 7 by the line with the colored box: (1) the PMS closes to bypass the coil current, and the fault current then flows

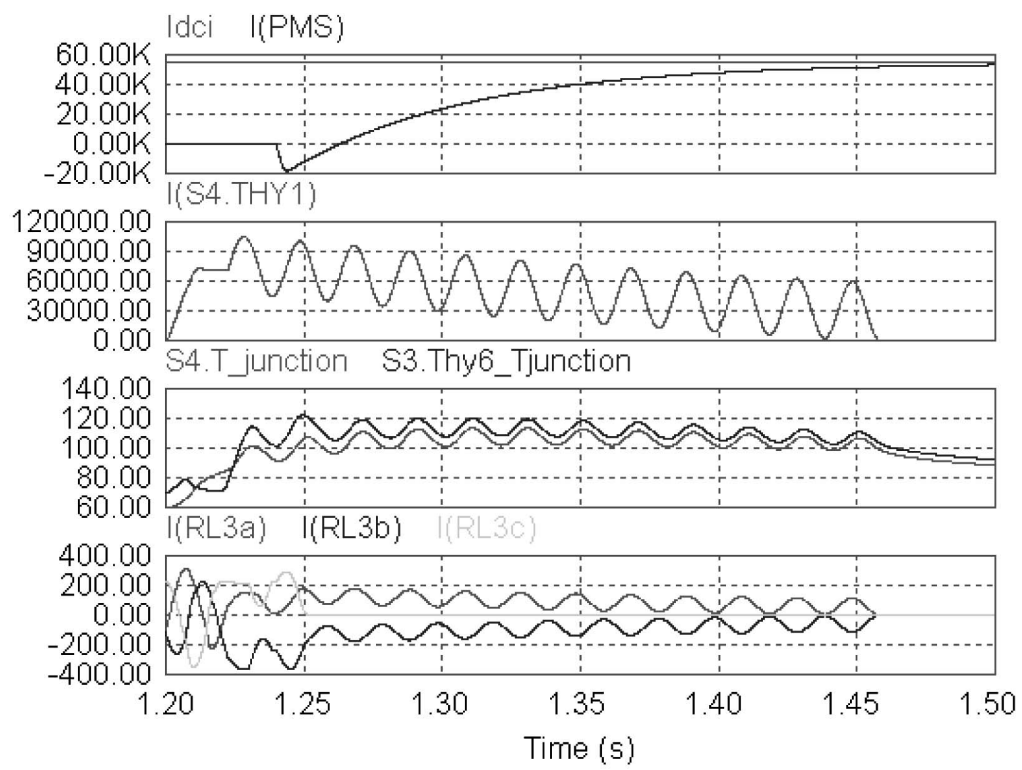

(a)

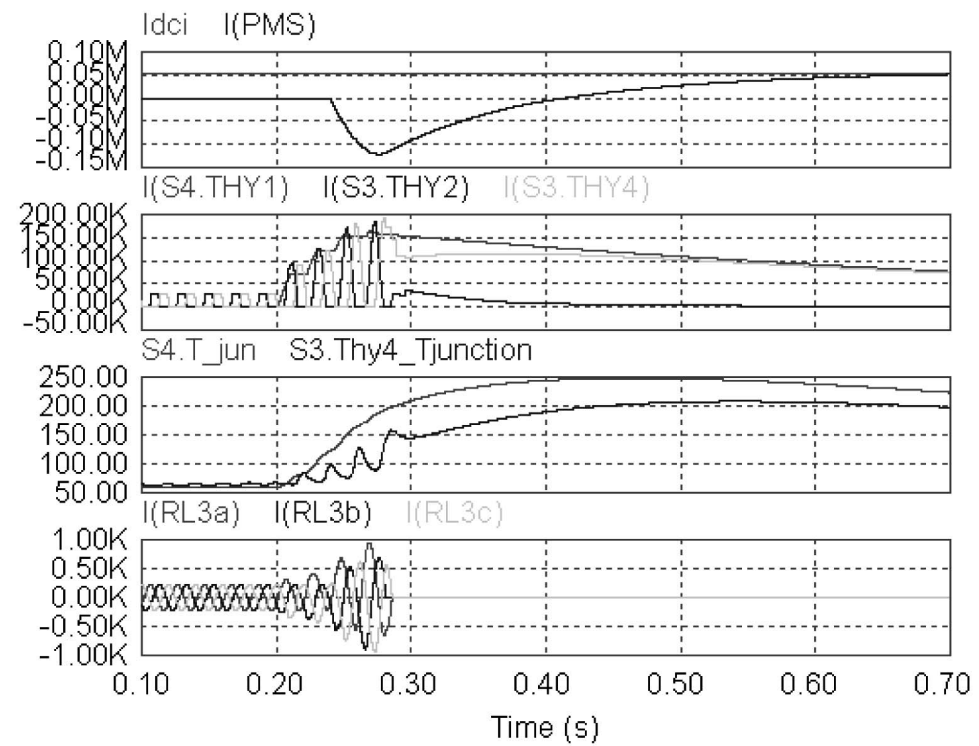

(b)

Fig. 8. (a) Simulation Results of the Single Fault Protection Sequence for the MC System during a Misfiring Fault. (Idci; Coil Current, I(PMS); PMS Current, S4_Tjunction; Junction Temperature of a Misfired Thyristor, S3.Thy6_Tjunction; Pair Thyristor of a Misfired Thyristor, I(RL3a,b,a); Primary ac Currents) (b) Simulation Results of the Double Fault Protection Sequence for the MC System during a Misfiring Fault. (I(S3.THY2), I(S3.THY4); Paired Thyristor Current of the Misfired Thyristor) 
through the thyristors and the coil current flows through PMS while the DC component is not transferred to the TR primary winding; (2) AC CB opens within $80 \mathrm{msec}$.

The simulation results of the two protection sequences for the MC system during a misfiring fault are shown in Fig. 8, and the results during a one-arm short (the most serious case among DC shorts) are shown in Fig. 9. In the simulation, the time delays of the every sequence are assumed to be follows:

- Single fault case; $20 \mathrm{msec}, 30 \mathrm{msec}, 40 \mathrm{msec}$ and 300 msec for the gate block, e-bypass on, PMS closed and ACCB open, respectively;

- Double fault case; $40 \mathrm{msec}$ and $80 \mathrm{msec}$ for the PMS closed and ACCB open, respectively.

The currents of the faults, bypass switches and valve thyristors were estimated with the simulation. The phase currents of the input line were also simulated to check the ACCB open condition. Finally, the temperatures of the worst thyristors were determined in order to establish the required number of parallel thyristors, assuming ABB

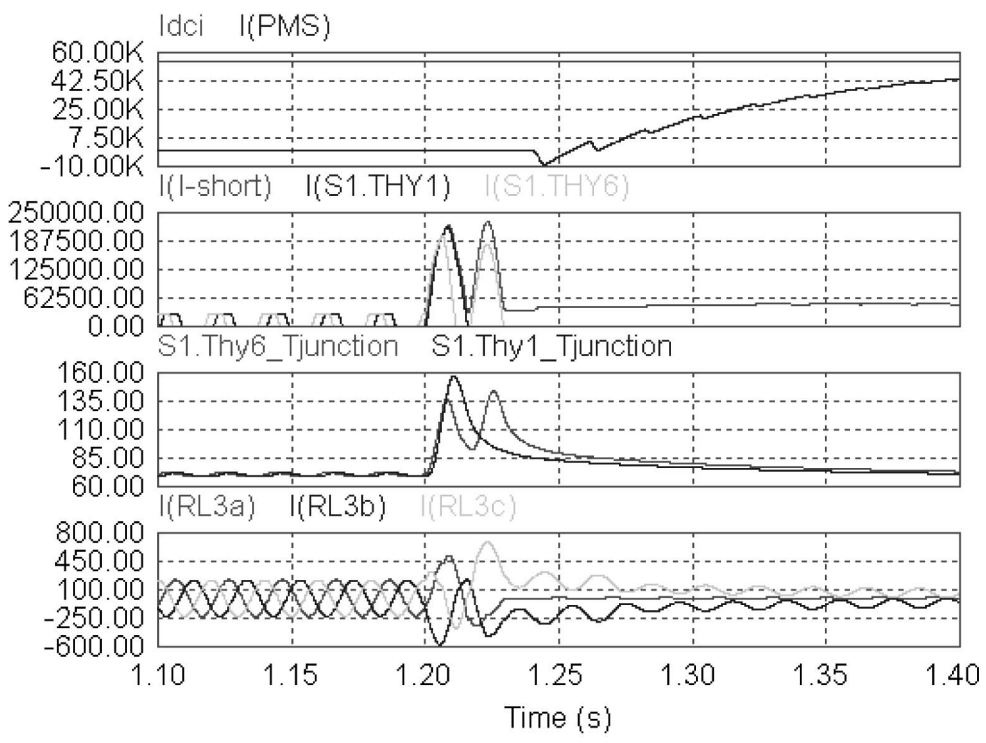

(a)

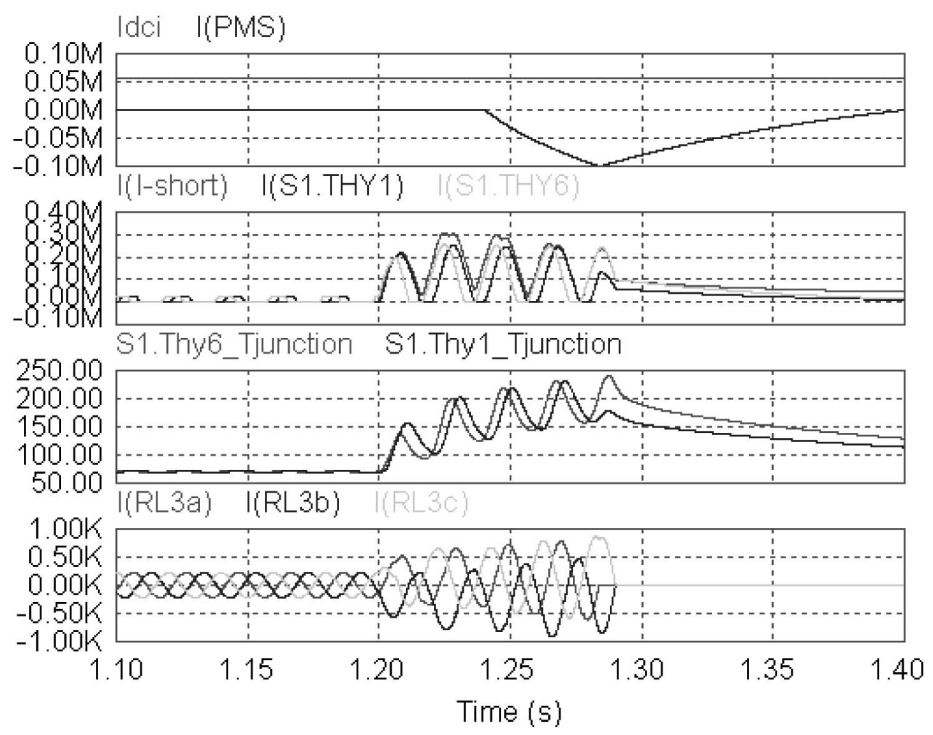

(b)

Fig. 9. (a) Simulation Results of the Single Fault Protection Sequence for the MC System during a Unit Module Arm Short. (I(I-Short); Short Current, I(S1.THY1, 2) Thyristor Current of the Arm Short Module, S1.Thy6 Tjunction; Thyristor Temperature of the Arm Short Module) (b) Simulation Results of the Double Fault Protection Sequence for the MC System during a Unit Module Arm Short 
45Q2800, an unbalance factor of 1.4 , an initial case temperature of $60^{\circ} \mathrm{C}$. The results indicate the need for at least seven thyristors in parallel.

\section{DETERMINATION OF THE CIRCUIT PARAMETERS}

To protect the converters from damage even during fault conditions, the number of thyristor in parallel and the size of the DCRs should be determined considering the scenario of the protection sequences. The thyristor valve size of the MC, BC and VS converters and the ebypass switches were determined for the worst fault scenario in the possible protection sequence. The worst case for the $\mathrm{MC}$ converters occurs during the double fault case with a misfiring fault, as shown in Fig. 8 (b). When the protection sequence succeeds, all possible damage of the thyristors is eliminated. With the worst case data for each converter, it is possible to estimate the number of thyristors for the valves for an arm depending on the junction temperature. The junction temperature of the thyristor is estimated using the PSIM model on the basis of the datasheet [5] from the manufacturers. The parallel number for the e-bypass switch of the MC converter is determined through the scenario with a parallel module arm short, as shown in Fig. 10.

The roles of the DCR in the current supply circuit in parallel are as follows: (1) limiting the ripple due to the phase shift, (2) avoiding a transient unbalance current in case of fast voltage regulation, (3) limiting the DC short current, (5) limiting any fault current if the reversed bridge misfires, and (6) avoiding the one-bridge-block situation due to a ripple in the circulation current operation. For the MC case, the simulation showed that the most critical role is to limit the misfiring fault current during a double fault condition; Fig. 11 shows the junction temperature with the DCR value during a double fault condition. The determined thyristor numbers of the converters and the size of the DCR with the same methodology applied to the $\mathrm{MC}$ are summarized in Table 2. The sizes were determined considering the most serious situation. The DCR sizes are also summarized in the table.

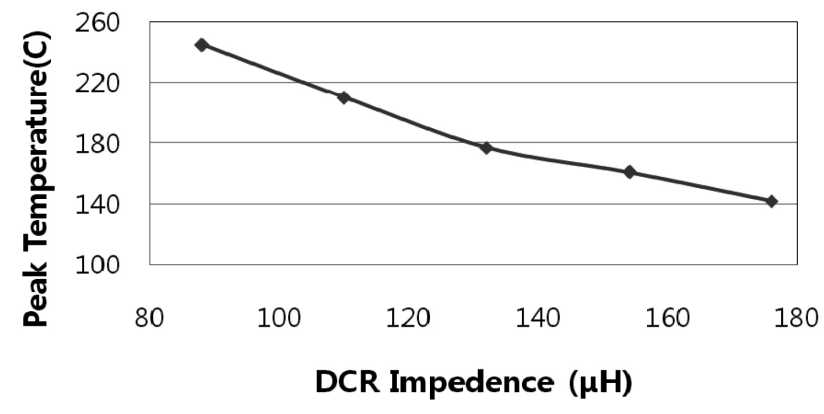

Fig. 11. The junction Temperatures Depending on the DCR

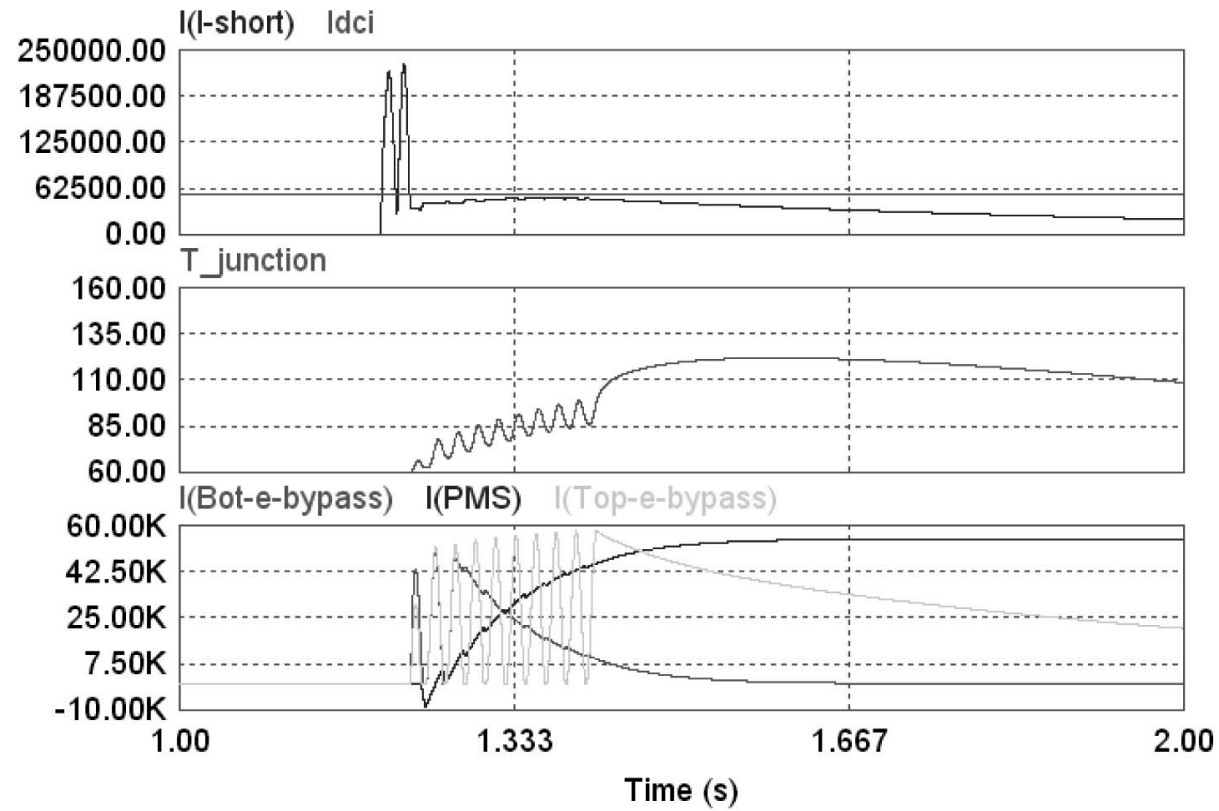

Fig. 10. The Simulation Result for a Unit Module Arm Short to Determine the Number of Thyristors Used in the e-bypass Switch. ( $\mathrm{T}$ Junction; the Thyristor Temperature of the e-bypass, I(Bot-e-bypass); Bottom e-bypass Current, I(Top-e-bypass);

Top e-bypass Current) 
$\mathrm{OH}$ et al., Protection Sequence of AC/DC Converters for ITER PF Magnet Coils

Table 2. Summary Table of the Thyristor Numbers Per Arm and the DCR Constants of the PF Coil Converters

\begin{tabular}{c|c|c|c|c|c|c}
\hline \multirow{2}{*}{} & \multicolumn{2}{|c|}{ Converter valve } & \multicolumn{2}{c|}{ E-bypass valve } & \multicolumn{2}{c}{ DCR constant } \\
\cline { 2 - 7 } & No. & temp $\left({ }^{\circ} \mathrm{C}\right)$ & No. & temp $\left({ }^{\circ} \mathrm{C}\right)$ & $\mu \mathrm{H}$ & $\mu$ \\
\hline MC converter & 8 & 180 & 5 & 125 & 130 & 110 \\
\hline BC converter & 4 & 155 & 2 & 110 & 552 & 176 \\
\hline VS converter & 8 & 145 & 1 & 125 & 210 \\
\hline
\end{tabular}

\section{CONCLUSION}

A protection sequence for the PF converters of an ITER power supply system was designed for single- and double-fault cases and was tested via circuit simulations. The design parameters, with which the converters and coils could be protected from damage during the protection sequence, were also determined. Other types of serious faults, such as trouble with the PMS or multiple faults, can lead to another scenarios, but these can be considered as "extremely unlikely events" during the ITER operation time.

\section{ACKNOWLEDGMENTS}

This research was supported by the National R\&D Program through the National Research Foundation of Korea (NRF) funded by the Ministry of Education, Science and Technology \& Ministry of Knowledge Economy (No. 2009-0081593). This paper does not reflect the final ITER design, but only the opinion of the author.

\section{NOMENCLATURE}

ITER International Tokamak for the Energy Research
PF Poloidal Field

PMS Protective Make Switch

$\mathrm{MC} \quad$ Main Converter

BC Booster Converter

VS Vertical Stability

FDU Fast Discharge Unit

MS Mechanical Switch

DCR DC Reactor

\section{REFERENCES}

[ 1 ] Design Description Document for the ITER Pulsed Power Supply System, DDD4.1 (2001) ITER Office

[2 ] Roshal A. et al., "Status of ITER Coil Power Supply Design" in Proc. of the EPIR-6 Conference, 1997, St. Petersburg, RF.

[ 3 ] Benfatto I. et al., "AC/DC Converters for the ITER Poloidal System" in Proc. of the $16^{\text {th }}$ SOFE, 1995, Champaign, IL, USA, pp. 658-661

[4 ] E. Gaio, R. Piovan, V. Toigo, I. Benffato, "Bypass Operation of the ITER AC/DC Converters for Reactive Power Reduction" presented at the $17^{\text {th }}$ SOFE, San Diego, CA, USA, 1997

[ 5 ] ABB Semiconductors, Doc. No. 5SYA 1050-02 May 07 